\title{
Neuromuscular blockade for early severe acute respiratory distress syndrome: Does sedation make the difference?
}

\author{
Yvonne Ilona Csanyi-Fritz, MD • \\ Robert Charles McDermid, MD
}

Received: 30 January 2012/Accepted: 16 February 2012/Published online: 1 March 2012

(C) Canadian Anesthesiologists' Society 2012

Drs. Needham and Brindley provided a thorough analysis of the paper by Dr. Papazian et al. regarding the use of cisatracurium in the early management of severe acute respiratory distress syndrome. ${ }^{1,2}$ However, it is important to consider that the observed benefit might be an unintended consequence of the sedative prescription rather than a direct effect of neuromuscular blockade (NMB). When converted to morphine equivalents, the control group received an average of $1,200 \mathrm{mg}$ more morphine over the first seven days than the NMB group $(5,000 \mu \mathrm{g} v s 3,800 \mu \mathrm{g}$ sufentanil equivalents; $P=0.54$ ). Conversely, patients in the NMB group received twice as much ketamine as those in the control group $(28,968 \mathrm{mg} v \mathrm{~s} 14,220 \mathrm{mg}$ over seven days, or an average of $2.5 \mathrm{mg} \cdot \mathrm{kg}^{-1} \cdot \mathrm{hr}^{-1}$ compared with $1.2 \mathrm{mg} \cdot \mathrm{kg}^{-1} \cdot \mathrm{hr}^{-1}$ for a $70 \mathrm{~kg}$ patient; $\left.P=0.06\right)$. Although neither difference reached statistical significance, the hemodynamic effects of these differences could be important, as opioids are potent venodilators while ketamine has venoconstricting properties. ${ }^{3,4}$

Unfortunately, the study only partially addressed this question. The control and NMB groups were similar with respect to the duration of vasoactive drug support, but the analysis of hemodynamic support did not consider accumulated fluid balance as a variable. Consequently, it is unknown whether differences in the amount of intravenous fluids were necessary to maintain hemodynamic stability. This may be relevant, as a restrictive fluid strategy has been

\footnotetext{
Y. I. Csanyi-Fritz, MD

University of British Columbia, Vancouver, Canada

R. C. McDermid, MD ( $₫)$

University of Alberta, Edmonton, Canada

e-mail: robmcdermid@telus.net
}

shown to improve outcomes in patients with acute lung injury when compared with a more liberal approach. ${ }^{5}$

The reasons behind the differences in the sedation prescription of the two groups are unclear. Perhaps the use of NMB influences the treating physician's perception of anesthetic requirements and the consequent prescription of ketamine is considered a dissociative anesthetic agent. Perhaps the elimination of the visible manifestations of respiratory distress results in less opioid administration. Regardless of the reason, attributing the benefit observed in this study to a direct effect of NMB may be premature in the absence of an assessment of differences in fluid administration.

Conflicts of interest None declared.

Editor's Note: The authors of the article, Can J Anesth 2012; 59: $105-8$, respectfully declined an invitation to submit a reply to the above Letter to the Editor.

\section{References}

1. Needham CJ, Brindley PG. The role of neuromuscular blocking drugs in early severe acute respiratory distress syndrome. Can J Anesth 2012; 59: 105-8.

2. Papazian L, Forel JM, Gacouin A, et al. Neuromuscular blockers in early acute respiratory distress syndrome. N Engl J Med 2010; 363: $1107-16$

3. Rouby JJ, Eurin B, Glaser P, et al. Hemodynamic and metabolic effects of morphine in the critically ill. Circulation 1981; 64: 53-9.

4. Hoka S, Takeshita A, Yamamoto K, Ito N, Yoshitake J. The effects of ketamine on venous capacitance in rats. Anesthesiology 1985; 62: $145-8$.

5. National Heart, Lung, and Blood Institute Acute Respiratory Distress Syndrome (ARDS) Clinical Trials Network; Wiedemann $H P$, Wheeler AP, Bernard GR, et al. Comparison of two fluidmanagement strategies in acute lung injury. N Engl J Med 2006; 354: $2564-75$ 